\title{
Maternal and Fetal Outcomes Following Labour at Term in Singleton Pregnancies with Meconium-Stained Amniotic Fluid: A Prospective Cohort Study
}

\author{
Julius Sama Dohbit1,2, Evelyne M. Mah',2, Felix Essiben"1,3, Edmond Mesumbe Nzene1, \\ Esther U. N. Meka1,2, Pascal Foumane1,2, Joel Noutakdie Tochie ${ }^{4 *}$, Benjamin Momo Kadia ${ }^{5}$, \\ Felix A. Elong6, Philip Njotang Nana1,3
}

\author{
${ }^{1}$ Department of Obstetrics and Gynecology, Faculty of Medicine and Biomedical Sciences, University of Yaounde I, Yaounde, \\ Cameroon \\ ${ }^{2}$ Gynaeco-Obstetric and Pediatric Hospital, Yaounde, Cameroon \\ ${ }^{3}$ Central Hospital of Yaounde, Yaounde, Cameroon \\ ${ }^{4}$ Department of Surgery and Anesthesiology, Faculty of Medicine and Biomedical Sciences, University of Yaounde I, Yaounde, \\ Cameroon \\ ${ }^{5}$ Foumbot District Hospital, Foumbot, Cameroon \\ ${ }^{6}$ Faculty of Health Sciences, University of Buea, Buea, Cameroon \\ Email: *joeltochie@gmail.com
}

How to cite this paper: Dohbit, J.S., Mah, E.M., Essiben, F., Nzene, E.M., Meka, E.U.N., Foumane, P., Tochie, J.N., Kadia, B.M., Elong, F.A. and Nana, P.N. (2018) Maternal and Fetal Outcomes Following Labour at Term in Singleton Pregnancies with Meconium-Stained Amniotic Fluid: A Prospective Cohort Study. Open Journal of Obstetrics and Gynecology, 8, 790-802. https://doi.org/10.4236/ojog.2018.89082

Received: June 26, 2018

Accepted: August 3, 2018

Published: August 6, 2018

Copyright $\odot 2018$ by authors and Scientific Research Publishing Inc. This work is licensed under the Creative Commons Attribution International License (CC BY 4.0).

http://creativecommons.org/licenses/by/4.0/

c) (†) Open Access

\begin{abstract}
Background: Meconium stained amniotic fluid (MSAF) is frequently encountered in obstetric practice. Literature on the subject is still poorly documented in the African setting. Objective: The aim of this study was to determine the maternal and fetal outcomes in case of meconium stained amniotic fluid observed during term labour. Materials and Methods: We conducted a prospective cohort study enrolling all consenting pregnant women with term singleton fetus in cephalic presentation admitted for labour with ruptured fetal membranes in the maternity units of the Yaoundé Central Hospital (YCH) and the Yaoundé Gynaeco-Obstetric and Pediatric Hospital (YGOPH) of Cameroon between December 2014 and April 2015. The exposed grouped was considered as participants having MSAF, while the non-exposed group comprised those with clear amniotic fluid (CAF). The two groups were monitored during labor using the WHO partograph, and then followed up till 72 hours after delivery. Variables studied included the colour and texture of amniotic fluid as well as maternal and fetal complications. Data was analyzed using Epi-info version 3.5.4. The chi-square and Fischer's exact tests were appropriately used to compare the two groups. A p-value less than $5 \%$ was considered statistically significant. Results: 2376 vaginal deliveries were rec-
\end{abstract}


orded during the study period among which MSAF was observed in 265 cases, hence a prevalence rate of MSAF of $11.15 \%$. Among these cases of MSAF, $52.1 \%$ was thick meconium and $47.9 \%$ was light meconium. Maternal morbidity was high in the group with MSAF; these included: Higher proportions of caesarean delivery $\left(\mathrm{RR}=2.35 \mathrm{p}<10^{-4}\right)$ and prolonged labor $(\mathrm{RR}=3 \mathrm{p}<$ $\left.10^{-4}\right)$. In this same group, the incidences of chorioamnionitis and puerperal sepsis were low $(0.94 \%$ and $0.70 \%$ respectively), although there was a three-fold higher risk that was not statistically significant $(\mathrm{RR}=3, \mathrm{P}=0.31)$. Fetal and neonatal outcomes were poorer in the MSAF group compared to the CAF group. The complications included fetal heart rate abnormalities, low Apgar score at the $5^{\text {th }}$ minute, need for neonatal resuscitation, neonatal asphyxia and neonatal infection which were significantly higher in the MSAF group (all $\mathrm{p}<0.05$ ). Meconium aspiration syndrome (MAS) was found in $2.34 \%$ of MSAF cases. Perinatal mortality was $2.34 \%$ and all cases of death occurred in the thick MSAF group. Conclusion: MSAF observed during labour is associated with increased perinatal morbidity and mortality. Its detection during labor should strongly indicate very rigorous intra partum and postpartum monitoring. This will ensure optimal management and reduction in the risks of complications.

\section{Keywords}

Meconium Stained Amniotic Fluid, Labour, Maternal and Neonatal Outcomes

\section{Introduction}

Amniotic fluid is a clear and transparent liquid in which the fetus lives. It is principally made up of water (96.4\%), mineral salts and organic substances [1] [2]. Its volume increases from $20 \mathrm{ml}$ at 7 weeks of gestation, to $980 \mathrm{ml}$ at 34 weeks and then drops to $540 \mathrm{ml}$ at 42 weeks. Its reabsorption is mainly by fetal swallowing and absorption through the amniotic membrane [2]. Two main abnormalities of amniotic fluid are volume and colour changes. Colour abnormality could be blood or meconium stained (MSAF) [2]. Meconium is the first stool of the fetus or neonate and its emission occurs between 24 and 48 hours of extra uterine life [3] [4] [5]. Certain pathological conditions can cause its emission before delivery, thus staining the amniotic fluid green. MSAF is a common finding in obstetric and neonatal practice with occurrence varying from $5 \%$ to $24.6 \%$ of deliveries [6]. Its incidence increases with gestational age, up to $30 \%$ at 40 weeks and $50 \%$ at 42 weeks [7] [8].

Although the exact cause of this MSAF is unclear, fetal distress, cord accidents and maternal hypertension have been identified as potential risk factors [9] [10]. Intrauterine emission of meconium has both fetal and neonatal consequences as well as maternal risks [5]. Studies done in India and Pakistan showed higher proportions of caesarean delivery, abnormal fetal heart rhythm, meconium inhalation syndrome (MIS), low Apgar score $(<7)$ at the fifth minute, neonatal sepsis and death in cases of MSAF [11] [12] [13]. In the USA and United King- 
doms, guidelines have been set for the management of cases with MSAF in order to reduce these complications [14] [15] [16]. These guidelines include continuous surveillance and amnioinfusion in cases of thick MSAF. These have led to a significant reduction in caesarean section rates [17] [18] [19]. With an extensive literature search, there is lack of studies assessing maternal and neonatal outcomes in case of MSAF in Cameroon. Therefore, this study aimed at determining the fetal, neonatal and maternal complications associated with MSAF in order to improve its management.

\section{Materials and Methods}

\subsection{Study Design and Setting}

This was a prospective cohort study which targeted pregnant women admitted in the labor wards of the maternity units of two university teaching hospitals of Cameroon; the Yaounde Central Hospital (YCH) and the Yaounde Gynaeco-Obstetric and Pediatric Hospital of Yaoundé (YGOPH). The study was conducted over a 5 months period from December 2014 to April 2015. Uniform and standard operating protocols for the management of labour were in use in both study settings.

\subsection{Participants, Sampling and Follow-Up}

We included all consecutive and consenting pregnant women presenting with singleton pregnancies at term, fetuses in cephalic presentation and ruptured fetal membranes and who gave their informed consent. We excluded women with pre-term or post term pregnancies, breech and other mal-presentations, multiple gestations, those admitted for elective caesarean, women with unknown last menstrual period and those with intra-uterine fetal death on admission. Cases of MSAF were considered as exposed while those with clear amniotic fluid (CAF) were considered as non-exposed. Women were matched based on parity. Participants were followed up during labor (using the WHO partograph), and 72 hours following delivery, checking for maternal, fetal and neonatal complications. Using a ratio of unexposed group to exposed group of 1, a 95\% confidence interval, minimum risk ratio of 2 for differences to be detected, the formula for difference in proportions [20] was used to calculate a minimum sample size was of 150 participants per group. The variables studied were (see appendix 1);1) Maternal sociodemographic data: maternal age, marital status, level of education and occupation. 2) Obstetric history: parity, gestational age, number of antenatal care visits, pregnancy pathologies. 3) Details of labour: mode of rupture of membranes (spontaneous or artificial), duration of membrane rupture, colour of amniotic fluid (green, yellow, meconium), consistency of amniotic fluid (light or thick), amniotic fluid odour (fetid or non fetid), fetal heart rhythm, APGAR score at the $1^{\text {st }}$ and $5^{\text {th }}$ minute. 4) Maternal complications: chorioamnionitis, prolonged labour ( $>12$ hours), instrumental delivery, cesarean section, pueperal infections. 5) Neonatal complications: fetal distress (fetal heart rate below 110 
beats per minute or above 160 beats per minute [21]), neonatal asphyxia (diagnosed based on the diagnosed based on the Modified Sarnat-Sarnat Score [22] and a five-minute Apgar score $\leq 3$ associated with neurological signs such as hypotonia, coma or convulsions [23]), neonatal resuscitation, admission into the neonatal unit and neonatal death.

\subsection{Data Management and Statistical Analysis}

Data was collected using a pretested questionnaire and analyzed using Epi-info version 3.5.4. The Chi-square and Fischer's exact tests were used to compare the two groups. A p-value of less than 5\% was considered statistically significant.

Ethical considerations. Ethical clearance was obtained from the Institutional Review Board of the Faculty of Medicine and Biomedical Sciences of the University of Yaounde I, Cameroon.

\section{Results}

\subsection{Characteristics of the Study Population}

A total of 2376 deliveries were registered during the study period. Among these there were 265 cases of MSAF, hence, a prevalence of $11.15 \%$ for MSAF. Of the 265 cases of MSAF, 52 cases (19.6\%) were excluded because of post term gestation, prematurity, breech presentation and multiple gestations. Two-hundred and thirteen (213) labour cases with CAF were matched to the remaining 213 cases of MSAF. The average age of the pregnant women was $27.72 \pm 5.34$ years with extremes of 15 and 40 years. There was no significant difference in ages between the two study groups (Table 1). The majority of the women were spinsters $(60.3 \%)$ and had at least attended secondary education (93.5\%). Out of the 426 cases analysed in this study, 248 babies were male and 178 female, giving a sex ratio of 1.39 with a male preponderance. This ratio was similar in the different subgroups. The mean gestational age at delivery was significantly greater in the MSAF group as compared to the CAF group (39.7 weeks vs 39.2 weeks: $\mathrm{P}=$ $0.0001)$. Gestational ages ranging between 40 to 42 weeks was significantly more common in the MSAF group than the CAF group ( $41.78 \%$ vs $26.76 \%, \mathrm{p}=0.0011$ ). The mean birth weight was $3277.11 \pm 493.59 \mathrm{~g}$. The weights were similar in the two groups. Cases of prolonged premature rupture of fetal membranes were significantly higher in the MSAF group $(\mathrm{p}=0.0047)$ (Table 2). Out of the 213 cases with MSAF, 111 (52.1\%) were thick meconium stained amniotic fluid and 102 (47.9\%) were lightly stained. In $23.5 \%$ of the cases, the amniotic fluid was initially clear at the beginning of labour before becoming meconium stained. Most (63.8\%) of the MSAF were detected during the active phase of labour. Nuchal cord and cord knots were respectively found in 21 (9.9\%) and 20 (9.39\%) cases of MSAF and CAF; the difference was not statistically significant (Table 3 ).

\subsection{Maternal Outcomes}

There was a significantly higher risk of prolonged labour and caesarean delivery 
Table 1. Socio-demographic characteristics of the study participants.

\begin{tabular}{|c|c|c|c|c|}
\hline \multirow[b]{2}{*}{ Variables } & \multirow[b]{2}{*}{$\begin{array}{c}\text { Total } \\
\text { N (\%) }[95 \% \text { CI }]\end{array}$} & \multicolumn{3}{|c|}{ Sub-groups } \\
\hline & & $\begin{array}{c}\text { MSAF } \\
\mathrm{n}(\%)\end{array}$ & $\begin{array}{l}\text { CAF } \\
\mathrm{n}(\%)\end{array}$ & $\mathrm{P}$-value \\
\hline \multicolumn{5}{|l|}{ Age (years): } \\
\hline$<20$ & $33(7.7)[5.5-10.8]$ & $18(8.45)$ & $15(7.04)$ & 0.5862 \\
\hline$[20-25[$ & $79(18.5)[15.0-22.6]$ & $43(20.19)$ & $36(16.90)$ & 0.3824 \\
\hline$[25-30]$ & $191(44.8)[40.1-49.7]$ & $88(41.31)$ & $103(48.36)$ & 0.1435 \\
\hline$>30$ & $123(28.9)[24.7-33.5]$ & $64(30.05)$ & $59(27.70)$ & 0.5926 \\
\hline \multicolumn{5}{|l|}{ Marital status } \\
\hline Married & $167(39.2)[34.6-44]$ & $88(41.31)$ & $79(37.09)$ & \\
\hline Spinster & $257(60.3)[55.5-65.0]$ & $125(58.69)$ & $132(61.97)$ & \\
\hline Divorced & $1(0.2)[0.0-1.5]$ & $0(00)$ & $1(0.47)$ & \\
\hline Widow & $1(0.2)[0.0-1.5]$ & $0(00)$ & $1(0.47)$ & \\
\hline \multicolumn{5}{|l|}{ Level of Education } \\
\hline None & $1(0.2)[0.0-1.5]$ & $0(00)$ & $1(0.47)$ & \\
\hline Primary & $27(6.3)[4.3-9.2]$ & $15(07.04)$ & $12(5.63)$ & \\
\hline Secondary & $209(49.1)[44.2-53.9]$ & $110(51.64)$ & $99(46.48)$ & \\
\hline University & $189(44.4)[39.6$ - 49.2] & $88(41.31)$ & $101(47.42)$ & \\
\hline \multicolumn{5}{|l|}{ Occupation } \\
\hline Housewife & $93(21.8)[18.1-26.1]$ & $48(22.54)$ & $45(21.13)$ & \\
\hline Trader & $81(19)[15.5-23.1]$ & $45(21.13)$ & $36(16.90)$ & \\
\hline Pupil/student & $138(32.4)[28.0-37.1]$ & $70(32.86)$ & $68(31.92)$ & \\
\hline Public employee & $77(18.1)[14.6-22.1]$ & $32(15.02)$ & $45(21.13)$ & \\
\hline Private employee & $37(8.7)[6.3-11.9]$ & $18(8.45)$ & $19(8.92)$ & \\
\hline
\end{tabular}

MSAF = meconium stained amniotic fluid; $\mathrm{CAF}=$ clear amniotic fluid.

in cases of MSAF and especially when the stain was thick; $30.5 \%$ and $44.6 \%$ respectively $(\mathrm{p}<0.001)$. Common indications of caesarean delivery were cephalo-pelvic disproportion and acute fetal distress. Chorioamnionitis, instrumental delivery and puerperal sepsis were also higher in cases of MSAF although the differences were not statistically significant $(P>0.05)$ (Table 4).

\subsection{Neonatal Outcomes}

The meconium inhalation syndrome (MIS) was found in 5 (2.34\%) cases of MSAF. The risks of low Apgar scores at the first and fifth minutes were multiplied by 8 times $(\mathrm{RR}=8.16, \mathrm{p}<0.001)$ and 3 times $(\mathrm{RR}=3.42, \mathrm{P}=0.0023)$ respectively, in cases of MSAF. Fetal heart rate abnormalities, neonatal infection and neonatal asphyxia were significantly higher in cases with MSAF. All ten cases $(4.7 \%)$ of perinatal deaths were in the group with MSAF (Table 5). 
Table 2. Obstetrical characteristics of the study participants.

\begin{tabular}{|c|c|c|c|c|}
\hline \multirow[b]{2}{*}{ Variables } & \multirow[b]{2}{*}{$\begin{array}{c}\text { Total } \\
\mathrm{n}(\%)[95 \% \mathrm{CI}]\end{array}$} & \multicolumn{3}{|c|}{ Sub-groups } \\
\hline & & $\begin{array}{c}\text { MSAF } \\
\mathrm{n}(\%)\end{array}$ & $\begin{array}{l}\text { CAF } \\
\mathrm{n}(\%)\end{array}$ & P-value \\
\hline \multicolumn{5}{|l|}{ Parity } \\
\hline Primiparous & $182(45.1)[40.3-49.9]$ & $96(45.07)$ & $96(45.07)$ & 1 \\
\hline Multiparous & $234(54.9)[50.1-59.7]$ & $117(54.93)$ & $117(54.93)$ & 1 \\
\hline \multicolumn{5}{|l|}{ Number of ANC } \\
\hline$<4$ & $71(16.7)[13.3-20.6]$ & $39(18.31)$ & $32(15.02)$ & 0.3623 \\
\hline$\geq 4$ & $355(83.3)[79.4-86.7]$ & $174(81.69)$ & $181(84.98)$ & 0.3623 \\
\hline \multicolumn{5}{|c|}{ Gestational age at delivery (weeks) } \\
\hline$[37-38]$ & $60(14.1)[11.0-17.8]$ & $19(8.92)$ & $41(19.25)$ & 0.0022 \\
\hline ]38 - 40] & $220(51.6)[46.8-56.5]$ & $105(49.30)$ & $115(53.99)$ & 0.3328 \\
\hline$] 40-42]$ & $146(34.3)[29.8-39.0]$ & $89(41.78)$ & $57(26.76)$ & 0.0011 \\
\hline \multicolumn{5}{|c|}{ Pathologies in pregnancy } \\
\hline Anaemia & $32(21.6)[15.3-9.1]$ & $14(6.57)$ & $18(8.85)$ & 0.4616 \\
\hline Malaria & $70(16.4)[13.1-0.4]$ & $42(19.72)$ & $28(13.15)$ & 0.0673 \\
\hline HIV infection & $13(3.1)[1.7-5.3]$ & $7(3.29)$ & $6(2.82)$ & 0.7781 \\
\hline Other STIs & $32(7.5)[5.3-10.5]$ & $22(10.33)$ & $10(4.69)$ & 0.0272 \\
\hline Hypertension & $27(6.3)[4.3-9.2]$ & $9(4.23)$ & $18(8.45)$ & 0.0739 \\
\hline History of $\mathrm{C} / \mathrm{S}$ & 49 (11.5) [8.7 - 15.0] & $24(11.27)$ & $25(11.74)$ & 0.8792 \\
\hline \multicolumn{5}{|c|}{ Mode of membrane rupture } \\
\hline Spontaneous & $193(45.3)[40.5-50.2]$ & $105(49.30)$ & $88(41.31)$ & 0.0976 \\
\hline Artificial & $233(54.7)[49.8-59.5]$ & $108(50.70)$ & $125(58.69)$ & 0.0976 \\
\hline \multicolumn{5}{|c|}{ Delay of membrane rupture } \\
\hline Premature rupture & $60(14.1)[11.0-7.8]$ & $28(13.15)$ & $32(15.02)$ & 0.5791 \\
\hline Prolonged rupture & $58(13.6)[10.6-7.3]$ & $39(18.31)$ & $19(8.92)$ & 0.0047 \\
\hline
\end{tabular}

ANC $=$ Antenatal care; $\mathrm{C} / \mathrm{S}=$ Cesarean section; $\mathrm{MSAF}=$ meconium stained amniotic fluid $\mathrm{CAF}=$ clear amniotic fluid; STIs = sexually transmitted infections.

Table 3. Characteristics of meconium stained amniotic fluid (MSAF).

\begin{tabular}{ccc}
\hline Characteristics & Number & Percentage \\
\hline Colour & & \\
Green & 111 & 52.1 \\
Yellow & 58 & 27.2 \\
Pure meconium & 44 & 20.7 \\
Consistency & & \\
Light & 102 & 47.9 \\
Thick & 111 & 52.1 \\
\hline
\end{tabular}




\begin{tabular}{ccc} 
Odour & & \\
Fetid & 11 & 5.2 \\
Non fetid & 202 & 94.8 \\
Chronology & & \\
AF initially clear & 50 & 23.5 \\
AF stained at start & 163 & 76.5 \\
Moment of detection & & \\
Before labour & 4 & 1.9 \\
Latent phase & 17 & 8 \\
Active phase & 136 & 63.8 \\
Expulsion phase & 9 & 4.2 \\
Per operative & 47 & 22.1 \\
\hline
\end{tabular}

$\mathrm{AF}=$ amniotic fluid.

Table 4. Effect of MSAF on maternal morbidity.

\begin{tabular}{ccccc}
\hline Variable & $\begin{array}{c}\text { MSAF } \\
\text { n (\%) }\end{array}$ & $\begin{array}{c}\text { CAF } \\
\text { n (\%) }\end{array}$ & RR [95\% CI $]$ & P-value \\
\hline Clinical chorioamniotitis & $3(1.4)$ & $1(0.5)$ & $3[0.50-17.95]$ & 0.3120 \\
Prolonged labour & $65(30.5)$ & $19(8.9)$ & $3.42[2.13-5.49]$ & $<0.001$ \\
Instrumental delivery & $6(2.82)$ & $1(0.47)$ & $6[0.73-49.41]$ & 0.1219 \\
Caesarean delivery & $95(44.6)$ & $48(22.5)$ & $1.97[1.48-2.64]$ & $<0.001$ \\
Puerperal infection & $3(1.4)$ & $0(00)$ & N/A &
\end{tabular}

N/A: not applicable (The relative risk could not be calculated because all the cases were in the exposed group).

Table 5. Fetal and neonatal morbidity in cases of MSAF.

\begin{tabular}{ccccc}
\hline & $\begin{array}{c}\text { MSAF(n=213) } \\
\mathbf{n}(\%)\end{array}$ & $\begin{array}{c}\text { CAF (n=213) } \\
\mathbf{n}(\%)\end{array}$ & RR [95\% CI $]$ & P-value \\
\hline Fetal heart beat anomaly & $71(33.3)$ & $29(13.6)$ & $2.90[1.79-4.72]$ & $<0.001$ \\
Apgar < 7 at 1 minute & $51(23.9)$ & $8(3.8)$ & $8.16[3.81-17.47]$ & $<0.001$ \\
Apgar < 7 at 5 minutes & $26(12.2)$ & $9(4.2)$ & $3.42[1.73-6.76]$ & 0.0023 \\
Neonatal resuscitation & $35(16.4)$ & $15(7.0)$ & $2.66[1.59-4.46]$ & 0.0026 \\
NNI & $28(13.1)$ & $5(2.3)$ & $5.6[2.46-12.71]$ & 0.0001 \\
NNA & $19(8.9)$ & $7(3.3)$ & $2.71[1.38-5.33]$ & 0.0186 \\
Admission in neonatology & $42(19.7)$ & $13(6.1)$ & $3.41[2.03-5.73]$ & $<0.001$ \\
Deaths & $10(4.7)$ & $0(00)$ & N/A &
\end{tabular}

NA: not applicable (The relative risk could not be calculated because all the cases were in the exposed group); NNI: Neonatal infection, NNA: Neonatal asphyxia. 


\section{Discussion}

The aim of this study was to determine the maternal and fetal outcomes in case of meconium stained amniotic fluid observed during labour of term singleton pregnancy in cephalic presentation. We found that the prevalence of MSAF was $11.15 \%$. MSAF was associated with a significant risk of caesarean delivery and prolonged labor. Also, MSAF was associated with the following fetal and neonatal complications; fetal heart rate abnormalities, low Apgar score at the $5^{\text {th }}$ minute, need for neonatal resuscitation, neonatal asphyxia and neonatal infection. Meconium aspiration syndrome (MAS) was found in $2.34 \%$ of MSAF cases. Perinatal mortality was $2.34 \%$ and all cases of death occurred in the thick MSAF group.

We found a prevalence of MSAF of $11.15 \%$. This finding is within the $5 \%$ to $24.6 \%$ interval stated in the literature [6], although higher than the $8.3 \%$ reported by Patil K.et al. in 2006 in India [18]. The higher prevalence observed in the current study could be explained by the fact that the study was conducted in two tertiary level hospitals in the capital city that receive referrals from the peripheral health facilities. Thick MSAF represented $52.1 \%$ and light MSAF represented $47.9 \%$. This concurs with findings from other low-and-middle income countries; $53 \%$ in Guinea [24] and 64.3\% in India [18]. The high frequency of thick MSAF could be due to the fact that evaluating amniotic fluid as lightly stained is very subjective and as such, the prevalence may greatly vary from one author to the other [9].

The mean gestational age was greater in the group with MSAF compared to the CAF group (39.7 vs 39.2 weeks: $\mathrm{p}=0.0001$ ). Moreover, the incidence of MSAF was $60.9 \%$ in cases with gestational age greater than 40 weeks. This positive correlation between advanced gestational age and the prevalence of MSAF concurs with previous observations made by Meis et al. [7] and Millar et al. [8] who found that the prevalence of MSAF could be up to $50 \%$ at 42 weeks of gestation.

Similar to studies done by by Erum et al. [11] and Salma et al. [12], we found MSAF to be associated with some maternal morbidities; a two-fold increase in caesarean delivery and a three-fold increase in chorioamnionitis and prolonged labour. We may attribute the high incidence of caesarean deliveries in this study to inadequate intrapartum fetal heart monitoring. As such, the presence of meconium in the amniotic fluid was an alarming sign of fetal distress and treated accordingly by emergency caesarean section.

After stratifying maternal morbidities according to the consistency of the MSAF, it was noted that thick MSAF compared to light MSAF and clear amniotic fluid (CAF) respectively increased the risk of caesarean delivery by 1.67 and 2.48. Similar results were found by Aparna et al. [9] and Nirmala et al. [13] in India where the risk of caesarean delivery was multiplied by 3 in case of thick MSAF. Likewise, all the cases of puerperal infections were found in the group with thick MSAF. Thick MSAF increased maternal morbidities significantly in cases of MSAF. 
Fetal morbidities were significantly higher in case of MSAF. These included non-reassuring fetal heart rhythm $\left(\mathrm{p}<10^{-4}\right)$, low Apgar scores at first and fifth minutes ( $\mathrm{p}<10^{-4}$ and $\mathrm{p}<10^{-2}$ respectively), neonatal infection (NNI) and neonatal asphyxia (NNA) ( $\mathrm{p}<10^{-3}$ and $\mathrm{p}<10^{-1}$ respectively). Similar results were obtained in India [9] and Guinea [25] where fetal heart rhythm anomaly was 5 times higher in case of MSAF. The various proportions of low Apgar scores $(<7)$ at the first minute were $3.8 \%, 23.9 \%$ and $36.9 \%$ in case of CAF, MSAF and thick MSAF respectively. In a similar order, low Apgar scores at the fifth minute were respectively $4.2 \%, 12.2 \%$ and $20.7 \%$ in case of CAF, MSAF and thick MSAF respectively. These differences in proportions were significantly higher in the group with thick MSAF both at the first and fifth minutes $\left\{1^{\text {st }}\right.$ minute $(\mathrm{RR}=9.83$; $\left.\mathrm{p}<10^{-4}\right)$ and $5^{\text {th }}$ minute $\left.\left(\mathrm{RR}=4.90 ; \mathrm{p}<10^{-2}\right)\right\}$. Patil et al. obtained similar results with low Apgar scores in 19\% of cases of MSAF [18]. Nirmala et al. [13] found low Apgar scores in 16\% of cases with MSAF and only in the first minute. The persistent difference in Apgar scores both at $1^{\text {st }}$ and $5^{\text {th }}$ minutes and in case of CAF observed in our series could suggest insufficient neonatal resuscitation. There was an overall drop in the proportions of low Apgar scores from the 1st to the $5^{\text {th }}$ minute. NNI $\left(\mathrm{RR}=5.6 ; \mathrm{p}=10^{-4}\right)$ and NNA $\left(\mathrm{RR}=2.71 ; \mathrm{p}<10^{-1}\right)$ were significantly more common in cases with MSAF. Noteworthy, the relative risk values are higher for thick MSAF compared to CAF; RR $=6.61$ for NNI and RR $=4.39$ for NNA. The observed value in the current study is higher than those recently obtained by Kumari et al. [26] and by Rajlaxmi et al. [27]. This high association of NNI and MSAF in our series could be explained by high proportions of prolonged premature rupture of membranes and resuscitation technics in the group with MSAF ( $\mathrm{p}=0.0047$ and $\mathrm{p}=0.0026$ respectively). Lastly, perinatal mortality was $4.69 \%$ in the group with MSAF versus $0 \%$ in the group with CAF; and all the cases were thick MSAF. Similar rates were obtained by Salma et al. [12] with risk of death multiplied by 2 in case of MSAF. Patil et al. [18] noted a mortality of $4 \%$, all in the group with thick MSAF.

Our results should be interpreted within the study's limitations. These include the sole use of fetal heart rhythm to diagnose acute fetal distress and the short term postpartum follow up period of 72 hours (coinciding with the hospital discharge of participants). As such, some complications could be missed because of this early exit from the hospital. However, based on well followed-up patients, we have used a cohort design to provide a contribution of level II scientific evidence to the scarcity on the outcomes of maternal and fetal outcomes in case of meconium stained amniotic fluid observed during labour of term singleton pregnancy in the sub-Saharan African region. These findings may guide obstetricians and midwives in making informed clinical decisions in their therapeutic strategies MSAF observed during labour in these resource-constrained environments.

\section{Conclusion}

MSAF observed during labour of term singleton pregnancies in cephalic presen- 
tations was associated with maternal and fetal complications. Its detection during labor warrants rigorous intra partum and postpartum monitoring for a timely diagnosis and management of these complications.

\section{Declaration of Interest}

The authors report no declaration of interest.

\section{Funding}

This research received no specific grant from any funding agency in the public, commercial, or not-for-profit sectors.

\section{References}

[1] Université Médicale Virtuelle Francophone (2011) Physiologie du liquide amniotique. Université médicale virtuelle francophone.

[2] Xavier, C., Pascal, V., Denis, T., Issam, B. and Francis, P. (2009) Physiologie du liquide amniotique. Dans: Tsunami, éditeur. Le manuel du résident obstétrique. Paris: Encyclopédie médico-chirurgicale, 99-119.

[3] Lopez, R.Y.C. and Martinez, R.D. (2002) In utéro defecation. Ultrasound in Obstetrics \& Gynecology, 19, 531.

[4] Collège National des Gynécologues et Obstétriciens Français. (2005) Extraits des mises à jour en gynécologie et obstétrique tome XXIX. Collège National des Gynécologues et Obstétriciens Français, Paris .

[5] Laxmi, N.I. (2010) Perinatal Outcome in Meconiun Stained Amniotic Fluid [Dissertation]. Rajiv Gandhi University of Health Sciences, Bangalore, 120 p.

[6] Cleary, G.M. and Wiswell, T.E. (1998) Meconiun Stained Amniotic Fluid and Meconiun Aspiration Syndrome, an Update. Pediatric Clinics of North America, 45, 511-529. https://doi.org/10.1016/S0031-3955(05)70025-0

[7] Meis, P.J., Hall, M., Marshak, J.R. and Hobel, C.J. (1978) Obstetrics \& Gynecology, 131, 509-513.

[8] Millar, F.C. and Read, J.A. (1981) Intrapartum Assessment of the Postdate Fetus. American Journal of Obstetrics and Gynecology, 141, 516-520. https://doi.org/10.1016/S0002-9378(15)33271-3

[9] Aparna, C., Miltra, P., Seth, S., Das, A., Subhadeep, B. and Joydip, P. (2013) Study on Risk Factors of Meconium Stained Amniotic Fluid and Comparison of Pregnancy Outcome in Clear and Meconium Stained Amniotic Fluid in a Tertiary Hospital, Kolkata India. International Journal of Biological and Medical Research, 4, 3084-3087.

[10] Dohbit, J.S., Foumane, P., Tochie, J.N., Mamoudou, F., Temgoua, M.N., Tankeu, R., Aletum, V. and Mboudou, E. (2017) Maternal and Neonatal Outcomes of Vaginal Breech Delivery for Singleton Term Pregnancies in a Carefully Selected Cameroonian Population: A Cohort Study. BMJ Open, 7, e017198.

https://doi.org/10.1136/bmjopen-2017-017198

[11] Erum, M.S., Sadaf, M. and Majid, A.S. (2010) Neonatal Outcome in Meconium Stained Amniotic Fluid-One Year Experience. Journal of Pakistan Medical Association, 60, 711-714.

[12] Salma, B.N. and Summiya, M. (2011) Association of Meconium Stained Amniotic 
Fluid with Perinatal Outcome in Pregnant Women of 37-42 Weeks Gestation. Pakistan Journal Of Surgery, 27, 292-298.

[13] Nirmala, D., Anshu, P., Urmila, D. and Ayali (2010) Meconium Staining of Amniotic Fluid, a Poor Indicator of Fetal Compromise. JK Science, 12, 184-186.

[14] University Hospitals of Morecambe Bay (2010) Meconium Liquor Management of Labour and Neonate. University Hospitals of Morecambe Bay, Morecambe Bay.

[15] Mid Essex Hospital Services (2010) Guideline for the Management of Meconium Stained Liquor. Mid Essex Hospital Services.

[16] Intensive Care Nursery. House Staff Manual (2004) Management of Infants Born through Meconiun Stained Amniotic Fluid. UCSF Children's Hospital, University of California, Oakland.

[17] Rathor, A.M., Singh, R. and Ramji, S. (2002) Randomized Trial of Amnioinfusion during Labour with Meconiun Stained Amniotic Fluid. BJOG, 109, 17-20. https://doi.org/10.1111/j.1471-0528.2002.01140.x

[18] Patil, K.P., Suargy, M.K. and Samatha, K. (2006) A One Year Cross Sectional Study of Management Practices of Meconium Stained Amniotic Fluid and Perinatal Outcome. The Journal of Obstetrics and Gynecology of India, 56, 128-130.

[19] Yoder, B.A., Kirsch, E.A., Barth, W.H. and Gordon, M.C. (2002) Changing Obstetric Practices Associated with Decreasing Incidence of Meconium Aspiration Syndrome. Obstetrics \& Gynecology, 99, 731-739. https://doi.org/10.1097/00006250-200205000-00011

[20] Lwanga, S.K., Lemeshow, S. and Organization, W.H. (1991) Sample Size Determination in Health Studies: A Practical Manual. http://www.who.int/iris/handle/10665/40062

[21] Committee on Obstetric Practice, American College of Obstetricians and Gynecologists (2005) ACOG Committee Opinion. Number 326, December 2005. Inappropriate Use of the Terms Fetal Distress and Birth Asphyxia. Obstetrics \& Gynecology, 106, 1469-1470. https://doi.org/10.1097/00006250-200512000-00056

[22] Sarnat, H.B. and Sarnat, M.S. (1976) Neonatal Encephalopathy Following Fetal Distress. A Clinical and Electroencephalographic Study. Archives of Neurology, 33, 696-705. https://doi.org/10.1001/archneur.1976.00500100030012

[23] American Academy of Pediatrics and American College of Obstetricains and Gynecologists (2002) Care of the Neonate. In: Gilstrap, L.C. and Oh, W., Eds., Guidelines for Perinatal Care, 5th Edition, American Academy of Pediatrics, Elk Grove Village, 196-197.

[24] Cecil, A.K., Apeawusu, B.A., Kariwiga, G. and Onenama, R. (1996) A Case-Control Study of Meconium Staining of Amniotic Fluid in Labour at Port Moresby General Hoapital to Determine Associated Risk Factors and Perinatal Outcome. PNG Medical Journal, 39, 297-309.

[25] Wiswell, T.E., Knight, G.R. and Finer, N.N. (2002) A Multicenter, Randomized, Controlled Trial Comparing Surfaxin (Lucinactant) Lavage with Standard Care for Treatment of Meconium Aspiration Syndrome. Pediatrics, 109, 1081-1087. https://doi.org/10.1542/peds.109.6.1081

[26] Kumari, S., Gupta, S.N., Mahato, I.P., Giri, R., Yadav, A., Thakur, A., et al. (2012) Maternal and Fetal Outcome in Term Labour with Meconium Stained Amniotic Fluid. Health Renaissance, 10, 198-202. https://doi.org/10.3126/hren.v10i3.7135

[27] Rajlaxmi, M. and Manika, A. (2013) Fetal Outcome in Meconium Stained Deliveries. Journal of Clinical and Diagnostic Research, 7, 2874-2876. 


\section{Appendix 1. Questionnaire}

Patient identification:

File $\mathrm{N}^{\circ}$ : Date:

Contact adresss: Age (years):

Marital Status: maried $\square$; single $\square$; divorced $\square$; widow $\square$

Level of education: not formal $\square$; primary $\square$; secondary $\square$; higher $\square$

Occupation: housewife $\square$ student $\square$ civil servant $\square$ private worker $\square$ independant $\square$

Monthly revenu (Fcfa):

$<25,000 \square \quad[25,000-50,000[\square \quad[50,000-100,000[\square \geq 100,000 \square$

Last mentrual period:_/___ Expected day of confinment: _/__ Gestational age (weeks-days)

Presenting complaint: labour pains $\square$; vaginal bleeding $\square$; lost of liquoir $\square$; others

\section{History of pregnancy:}

No of antenatal care visits: VIH serology: negative $\square$ positive $\square$

Level of haemoglobin: $<10 \mathrm{~g} / \mathrm{dl} \square$; $\geq 10 \mathrm{~g} / \mathrm{dl}$

Pathologies in pregnanacy: anaemia $\square$; malaria $\square$; urinary infection $\square$; diabetes $\square$; Hypertension $\square$ others

Gravida ___ Para ; No of past cesarean sections:

Medical History: None $\square$; Hypertension: Yes $\square /$ No $\square$; diabetes: Yes $\square /$ No $\square$

Cardiopathy: Yes $\square /$ No $\square$ others

Monitoring of labour (partograph)

Mode of rupture of membranes: Spontanous $\square$ Artificial $\square$

Delay of rupture of membranes: Premature Rupture: Yes $\square /$ No

Prolonged Rupture: Yes $\square /$ No $\square$

Nature of liquoir: Clear $\square$ /Meconial $\square$ If meconial, colour: green $\square$; yellow $\square$; purulent $\square$

Consistency of liquoir: light $\square$ thick $\square$; Odour of liquoir: foul smelling $\square$ not foul smelling $\square$

Moment of detection of MSAF: before onset of labour $\square$; latent phase $\square$; active phase $\square$; expulsion phase $\square$; intra operative $\square$

MSAF noticed immediately at membrane rupture $\square /$ Initial clear liquoir followed by MSAF

Fetal heart rate anomaly during labour: Yes $\square /$ No $\square$

$\begin{array}{lll}\text { If Yes: Tachycardia } \square & \text { Bradycardia } \square & \text { Deceleration } \square \\ \text { If deceleration: type I } \square & \text { type II } \square & \text { type III } \square\end{array}$

Maternal fever (temp > 37.8): Yes $\square /$ No $\square$; Maternal tachycardia (>100): Yes $\square /$ No $\square$ 
Uterine pain on palpation: Yes $\square$ /No $\square$ Clinical chorioamnionitis: Yes $\square /$ No

Mode of delivery:

Normal vaginal delivery $\square$;

Instrumental $\square$ (Indication: fetal distress $\square$ cephalopelvic disproportion $\square$; fatigue $\square$ others

Cesaerian section $\square$ (Indication: fetal distress $\square$; cephalopelvic disproportion $\square$; others

Duration of labour: Normal $\square$ Prolonged $\square$

If prolonged: $1^{\text {st }}$ stage $\square$ duration $2^{\text {nd }}$ stage $\square$ duration $3^{\text {rd }}$ stage duration

Placenta: weight $(\mathrm{g})$ ; meconial stained: Yes $\square / \mathrm{No} \square$

Calcifications: Yes $\square /$ No $\square$; other anomalies

Umbilical Cord: meconial stained: Yes $\square /$ No $\square$; cord knot: Yes $\square /$ No $\square$

Cord round neck: Yes $\square$ /No $\square$; cord prolapse: Yes $\square /$ No $\square$ other anomalies

State of newborn:

Gender: Male $\square$ Female $\square$; Weight $(\mathrm{g})$

APGAR: $1^{\text {st }} \min$ $/ 10 ; 5^{\text {th }} \mathrm{min}$ $/ 10$

Resuscitation: Yes $\square /$ No $\square$; if yes: Duration $\min$, Method

Respiratory distress: Yes $\square /$ No $\square$; Neonatal Asphyxia: Yes $\square /$ No $\square$

Meconium inhalation syndrome: Yes $\square \square /$ No $\square$; Neonatal Infection: Yes $\square / \mathrm{No} \square$

Neonatal unit admission: Yes $\square /$ No $\square$;

Neonatal death: Yes $\square /$ No $\square$

Follow-up of the mother and newborn

\begin{tabular}{ccc}
\hline \multirow{2}{*}{ Days - date } & Newborn & Mother \\
\cline { 2 - 3 } & Complications & Post partum Complications \\
\hline Day 1 & NNI $\square$ NNA $\square$ RD $\square$ MIS $\square \operatorname{died} \square$ Non $\square$ & Puerperale infection:Yes_No_ \\
Day 2 & NNI $\square$ NNA $\square$ RD $\square$ MIS $\square \operatorname{died} \square$ Non $\square$ & Yes_No_ \\
Day 3 & NNI $\square$ NNA $\square$ RD $\square$ MIS $\square \operatorname{died} \square$ Non $\square$ & Yes_No_
\end{tabular}

NNI: Neonatal infection, NNA: Neonatal asphyxia, RD: Respiratory distress, MIS: Meconium inhalation syndrome. 